November 2017

\title{
Tackling the health burden of air pollution in South Asia
}

Bhargav Krishna

Public Health Foundation of India, Gurgaon, India

Kalpana Balakrishnan

Sri Ramachandra University, Chennai, India

Amna R. Siddiqui

Aga Khan University, rehana.siddiqui@aku.edu

Bilkis A. Begum

Atomic Energy Centre, Dhaka, Bangladesh

Damodar Bachani

Public Health Foundation of India, Gurgaon, India

See next page for additional authors

Follow this and additional works at: https://ecommons.aku.edu/pakistan_fhs_mc_chs_chs

Part of the Community Health Commons, and the Public Health Commons

\section{Recommended Citation}

Krishna, B., Balakrishnan, K., Siddiqui, A. R., Begum, B. A., Bachani, D., Brauer, M. (2017). Tackling the health burden of air pollution in South Asia. BMJ, 359(j5209), 1-5.

Available at: https://ecommons.aku.edu/pakistan_fhs_mc_chs_chs/349 
Authors

Bhargav Krishna, Kalpana Balakrishnan, Amna R. Siddiqui, Bilkis A. Begum, Damodar Bachani, and Michael Brauer 


\title{
Tackling the health burden of air pollution in South Asia
}

\author{
Bhargav Krishna and colleagues call for health driven, multisectoral policy making with defined \\ air quality targets to curb the impact of air pollution exposure in South Asia
}

A ir pollution exposure is the second most important risk factor for ill health in South Asia, contributing to between $13 \%$ and $21.7 \%$ of all deaths and approximately 58 million disability adjusted life years (DALYs) through chronic and acute respiratory and cardiovascular illnesses. ${ }^{1}$ Of the top 30 cities in the world with the poorest air quality in 2016, 17 are in South Asia. ${ }^{2}$ The impact of air pollution transcends boundaries. The "brown cloud"-caused by pollution from carbon aerosols-is a phenomenon captured in satellite images of atmospheric haze over South Asia, as well as China. South Asia has one of the highest concentrations of black carbon emissions from cars and trucks, cooking stoves, and industrial facilities. In addition to their effect on health, black carbon particles are a short lived climate pollutant with a possible impact on precipitation patterns and on the Himalayan glacier system, which threatens water resources in the region. ${ }^{3}$

Collective regional action to monitor air quality and implement evidence based policies and interventions is needed. While countries have introduced promising initiatives in recent years, comprehensive health centred strategies are lacking. We present the status of air pollution and health effects in South Asia, and propose urgent, concerted action across sectors to achieve recommended air quality standards for the people of the region.

\section{Air pollution exposure and trends}

Household (indoor) and ambient (outdoor) air pollution both contribute to ill health.

\section{KEY MESSAGES}

- Air pollution is a major risk factor for ill health in South Asia

- The interconnected nature of the South Asian airshed necessitates regional cooperation

- Tackling the sources of air pollution requires systematic collection of air quality data and a scientific approach to air quality management

- Tackling the health burden of air pollution will require coordinated, multisectoral response, using a "health in all policies" framework

\begin{tabular}{|c|c|c|c|c|}
\hline & \multicolumn{2}{|l|}{$\mathrm{PM}_{10}\left(\mu \mathrm{g} / \mathrm{m}^{3}\right)$} & \multicolumn{2}{|l|}{$\mathrm{PM}_{2.5}\left(\mu \mathrm{g} / \mathrm{m}^{3}\right)$} \\
\hline & $\begin{array}{l}\text { Annual mean } \\
\text { concentration }\end{array}$ & $\begin{array}{l}24 \mathrm{~h} \\
\text { concentration }\end{array}$ & $\begin{array}{l}\text { Annual mean } \\
\text { concentration }\end{array}$ & $\begin{array}{l}24 \mathrm{~h} \\
\text { concentration }\end{array}$ \\
\hline Interim target-1 & 70 & 150 & 35 & 75 \\
\hline Interim target-2 & 50 & 100 & 25 & 50 \\
\hline Interim target-3 & 30 & 75 & 15 & 37.5 \\
\hline Air quality guideline* & 20 & 50 & 10 & 25 \\
\hline \multicolumn{5}{|c|}{$\begin{array}{l}{ }^{1} \mathrm{PM}_{10} \text { : Airborne particulate matter smaller than } 10 \mu \mathrm{m} \text { (includes both coarse and fine particles that enter the respiratory tract). } \\
{ }^{2} \mathrm{PM} \mathrm{M}_{2.5} \text { : Airborne particulate matter smaller than } 2.5 \mu \mathrm{m} \text {. } \\
{ }^{3} \text { Interim targets represent incremental steps in a progressive reduction of air pollution. Annual mean concentrations } \\
\text { provide an estimate of long term exposure for comparison. } \\
{ }^{4} \text { * Lowest levels at which total, cardiopulmonary, and lung cancer mortality have been shown to increase in response to } \\
\text { long term exposure to } \mathrm{PM}_{2.5} \text {. }\end{array}$} \\
\hline
\end{tabular}

Rural and urban areas are both affected by poor air quality. However, the sources and pollutant profiles vary. For instance, use of cooking fuels varies between urban and rural households, vehicular density is higher in cities, and different climate and geography across the region affect levels of air pollution.

\section{Household air pollution}

Approximately $74 \%$ of South Asian households use solid fuels such as wood, dung, or coal for cooking and heating. ${ }^{4-6}$ These are inefficient fuels and their use in open fires or leaky stoves contributes to high levels of indoor smoke. Studies on indoor air pollution in South Asia show average daily $\mathrm{PM}_{2.5}$ concentrations range from 300 $\mu \mathrm{g} / \mathrm{m}^{3}$ to $3000 \mu \mathrm{g} / \mathrm{m}^{3},{ }^{578}$ which is much higher than is recommended by the World Health Organization (box 1). ${ }^{9}$ The proportion of households relying on solid fuels has decreased over the past few decades (fig 1); however this decrease has largely been offset by the increase in population. ${ }^{10}$

The type of fuel and stove, kitchen area ventilation, quantity of fuel, age, gender, and time spent near the cooking area influence exposure within and between households. Women and children tend to have higher exposure. Use of solid cooking fuels also contributes to ambient air pollution as a result of emissions carried outdoors. In densely populated communities of India, household air pollution has been estimated to contribute to nearly $27 \%$ of ambient air pollution. ${ }^{11}$

Since few studies report direct measures of household air pollution, ${ }^{7}$ trends are estimated (for purposes of comparative risk assessment) using spatiotemporal Gaussian process regression modelling that incorporates data on the proportion of solid fuel use in each country from nationally representative household surveys and select co-variates, including maternal education and proportion of population living in urban areas ${ }^{12}$

\section{Ambient air pollution}

The population in South Asia, with the exception of Sri Lanka, is among the most highly exposed to $\mathrm{PM}_{2.5}$ in the world (table 1). Estimates from the Global Burden of Disease Study 2015 (GBD) indicate that the population weighted mean ambient $\mathrm{PM}_{2.5}$ concentration in South Asia* was 73 $\mu \mathrm{g} / \mathrm{m}^{3}$, compared with the global average of $44 \mu \mathrm{g} / \mathrm{m}^{3}$. Nearly $99.9 \%$ of the South Asian population is living in areas with poorer air quality than the minimum standards recommended by WHO (box 1).

Population weighted $\mathrm{PM}_{2.5}$ concentrations have increased by $24 \%$ in South Asia between 1990 and 2015, with an increase in all countries except Pakistan and Sri Lanka (fig 2). Ozone concentrations

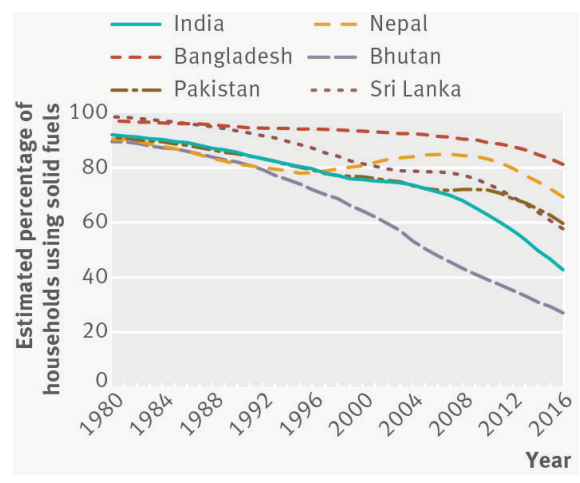

Fig 1 | Trends in estimated percentage of households using solid fuels in South Asian countries 


\begin{tabular}{|c|c|c|c|c|c|c|}
\hline Country & $\begin{array}{l}\text { Population } \\
\text { (millions) }\end{array}$ & 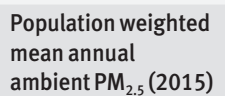 & $\begin{array}{l}\text { Percentage increase in } \\
\text { population weighted mean } \\
\text { annual } \mathrm{PM}_{2.5}(1990 \text { to } 2015)\end{array}$ & $\begin{array}{l}\text { Percentage of population } \\
\text { in } 2015 \text { living in areas } \\
\text { exceeding WHO IT-1 }\end{array}$ & $\begin{array}{l}\text { Population weighted } \\
\text { seasonal mean } \\
\text { ozone (2015) }\end{array}$ & $\begin{array}{l}\text { Percentage increase in } \\
\text { population weighted seasonal } \\
\text { mean ozone (1990 to 2015) }\end{array}$ \\
\hline India & 1282.3 & 74 & 23 & 89.9 & 76 & 23 \\
\hline Bangladesh & 148.9 & 89 & 39 & 99.9 & 74 & 25 \\
\hline Pakistan & 202.8 & 65 & -4 & 94.5 & 69 & 17 \\
\hline Nepal & 31.3 & 75 & 34 & 90.6 & 78 & 26 \\
\hline Bhutan & 0.9 & 56 & 40 & 81.6 & 69 & 25 \\
\hline Sri Lanka & 19.5 & 28 & -7 & 21.9 & 54 & 17 \\
\hline South Asia* & 1693.8 & 73 & 24 & 91.2 & 74 & 21 \\
\hline Global & 7155.5 & 44 & 10 & 50.2 & 61 & 7 \\
\hline
\end{tabular}

* Here and elsewhere South Asia refers to the GBD regional definition which includes Bangladesh, Bhutan, India, Nepal, and Pakistan. Data for Sri Lanka added separately. WHO IT-1 is World Health Organization $\mathrm{PM}_{2.5}$ Interim Target -1 of $35 \mu \mathrm{g} / \mathrm{m}^{3}$ (annual average).

have also increased across the region at a rate exceeding the global increase.

The sources of ambient air pollution vary across the region, and across rural and urban settings. Vehicular emissions, construction and road dust, residential biomass use, and industrial emissions are major contributors. ${ }^{13-16}$ The main sources of fuel used for power generation such as coal, natural gas, and oil can influence air quality. In Bangladesh, localised sources like brick kilns and motorised transport contribute to the base pollution load throughout the year. Additionally, in winter, transboundary transport of particulate matter across the Indo-Gangetic Plain airshed contributes to higher levels of $\mathrm{PM}_{2.5}{ }^{14}$ Similarly, in Pakistan, transboundary transport of dust and pollutants from the Arabian Peninsula ${ }^{1516}$ and from India ${ }^{17}$ is noted to cause episodic spikes in $\mathrm{PM}_{10}$ and $\mathrm{PM}_{2.5}$ levels.

\section{Impact on health}

Exposure to ambient $\mathrm{PM}_{2.5}$ was the third ranking risk factor for mortality (1.4 million deaths, $10.6 \%$ of total deaths) and DALYs (5.8\% of total DALYs) in South Asia in 2015. Household air pollution ranks fourth (5.5\% of DALYs and 1.2 million deaths, $9.6 \%$ of total deaths).${ }^{18}$ No studies

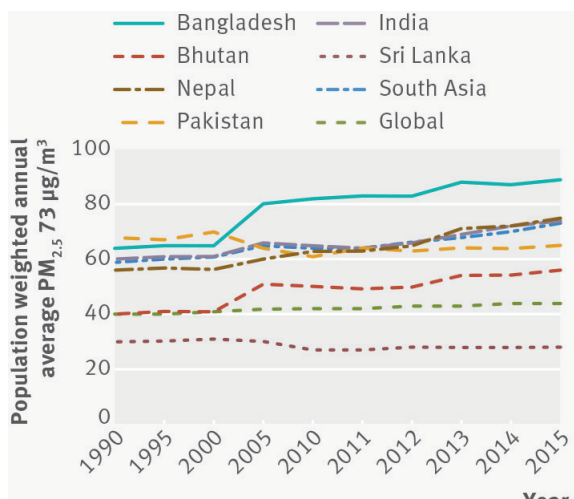

Fig 2 | Trends in annual average population weighted $\mathrm{PM}_{2.5}$ exposure in South Asia, 1990 to 2015 . These figures were adapted from estimates developed for the Global Burden of Disease (2015) study to date have evaluated the health impacts of co-exposure to household and ambient air pollution.

Over the past 25 years, deaths attributable to ambient $\mathrm{PM}_{2.5}$ exposure have increased, with some acceleration since 2010 (fig 3). Increase in $\mathrm{PM}_{2.5}$ levels, population growth, and ageing contribute to this trend. Bangladesh, India, and Pakistan have a higher burden because of larger populations, high exposures, and increasing numbers of people affected by chronic diseases. Common diseases affected by air pollution include ischaemic heart disease, stroke, acute lower respiratory infections, chronic obstructive pulmonary disease, and lung cancer. Deaths attributable to household air pollution have remained high and relatively stable with only a modest increase from 1.1 million to 1.2 million between 1990 and 2015.

The age standardised attributable death rates indicate a small decrease, from 158 deaths per 100000 in 1990 to 133 per 100000 in 2015, while there has been a large decrease in the rate of attributable DALYs (fig 4) between 1990 and 2010, possibly driven by a decrease in the incidence of acute lower respiratory infections. Deaths attributable to ozone exposure, while much lower than those

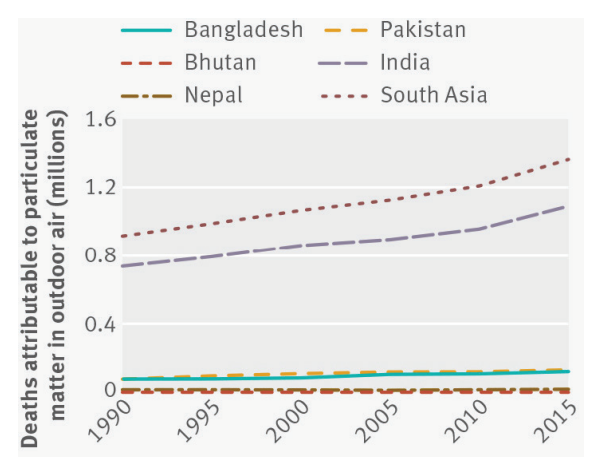

Year

Fig 3 | Trends in deaths attributable to ambient PM $_{2.5}$ in South Asia, 1990 to 2015. These figures were adapted from estimates developed for the Global Burden of Disease (2015) study. attributable to $\mathrm{PM}_{2.5}$ exposure, have increased sharply throughout South Asia from 48000 in 1990 to 122000 in 2015 (a $154 \%$ increase) driven by increased exposure and increasing rates of chronic obstructive pulmonary disease in the region, and in India especially.

Air pollution propagates existing environmental vulnerabilities. ${ }^{19}$ Children and older people are particularly vulnerable. Air pollution exposure results in low birth weight, ${ }^{20}$ poor lung development in children, ${ }^{21}$ mortality from respiratory infections, ${ }^{22}$ and may also affect cognitive development. ${ }^{23}$ Older people are more likely to develop chronic respiratory and cardiac illnesses, and are more susceptible to heart attacks and strokes from long term exposure, and during episodic high pollution events. ${ }^{24}$ Lower socioeconomic groups are more susceptible to insults from air pollution exposure for a variety of reasons including occupation and housing. ${ }^{2519}$

\section{Fragmented efforts to reduce air pollution}

With the lack of high quality data on air pollution and on health effects in South Asian countries, interventions are usually ad hoc, and their impact cannot be assessed. Public

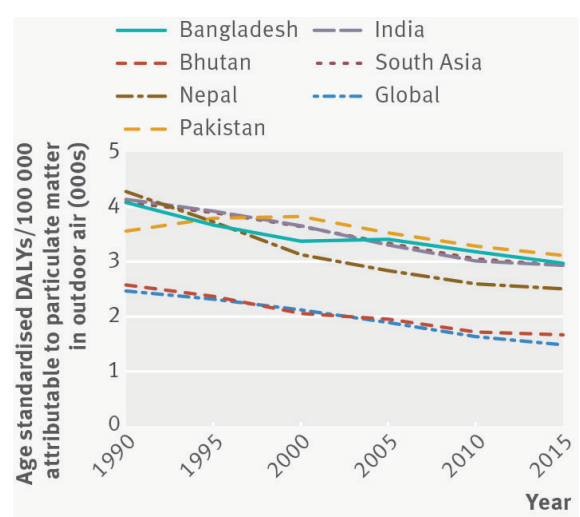

Fig 4 | Trends in age standardised

DALYs/100 000 attributable to ambient $\mathrm{PM}_{2.5}$ exposure in South Asia, 1990 to 2015. These figures were adapted from estimates developed for the Global Burden of Disease (2015) study 
and media attention on levels of air pollution in South Asian cities have led to sporadic measures; however, a robust strategy with targeted reductions in pollutant levels is lacking.

\section{Availability and quality of air pollution data} Continuous ground monitoring of air quality across a range of locations is essential to understand the concentration of pollutants at different time points and implement control strategies. South Asian countries lag far behind global standards in the density and coverage of air quality monitoring networks. Routine monitoring of $\mathrm{PM}_{2.5}$ and ozone in the region is minimal. Epidemiological studies currently rely on modelled exposure estimates based on satellite data.

In India, for example, the National Air Quality Monitoring Program collects pollutant data twice a week from 629 stations across 264 cities, with 35 cities also hosting continuous air quality monitoring stations. ${ }^{26}$ Monitoring is restricted to urban areas with virtually none carried out in rural areas. There are also challenges with the data collected, including calibration errors, gaps in data, and wide variation in uptime of monitoring stations.

\section{Research on health outcomes}

A growing body of literature from South Asia indicates an association between short term exposure to air pollution and a range of health outcomes such as decrease in lung function, respiratory symptoms, emergency department visits, and mortality. To date, however, no direct epidemiological studies of long term exposure to ambient $\mathrm{PM}_{2.5}$ and mortality from chronic diseases in South Asia have been published. The evidence on acute and chronic health effects at the high levels of exposures commonly encountered in South Asian countries needs to be strengthened. ${ }^{27} 28$

Large scale household surveys, census, and vital registration systems are the primary sources of data on mortality in South Asia. Incomplete or inconsistent recording of cause of death, and structural deficiencies in data collection result in under-reporting of deaths, especially in rural areas, and thereby provide little understanding of the impact of air pollution.

\section{Air quality management and exposure reductions}

South Asian countries have taken some steps to address specific categories of emissions and exposures (table 2) and improve air quality. There is no coherent strategy, however, with defined targets for air quality and regular monitoring to understand the impact of these measures. ${ }^{29}$ Political will and effective governance are central to tackling the problem.

\begin{tabular}{|c|c|c|}
\hline Country & Target sector & Policies or interventions \\
\hline \multirow[t]{4}{*}{ Pakistan ${ }^{30-34}$} & Transport & $\begin{array}{l}\text { Introduction of Euro IV standards for exhaust emissions from passenger cars } \\
\text { Retrofitting diesel buses and trucks with PM emission controls }\end{array}$ \\
\hline & Power & Coal gasification, carbon sequestration \\
\hline & Industry & $\begin{array}{l}\text { Gas to replace fuel oil and coal } \\
\text { Low sulphur furnace oil and diesel }\end{array}$ \\
\hline & Domestic & Promote cleaner cooking and increased use of natural gas \\
\hline \multirow[t]{5}{*}{ India ${ }^{35-40}$} & Transport & Introduction of Euro VI equivalent standards for vehicles and fuels \\
\hline & Industry and power & Emissions standards for various industries \\
\hline & Domestic & LPG connections to 50 million rural households by 2019 \\
\hline & $\begin{array}{l}\text { Localised } \\
\text { action plans }\end{array}$ & $\begin{array}{l}\text { Graded Response Action Plan for Delhi } \\
\text { Comprehensive Action Plan for pollution control in the National Capital Territory }\end{array}$ \\
\hline & Brick kilns & Transition to “induced draft zig-zag”" technology \\
\hline \multirow[t]{3}{*}{ Bangladesh $^{41-43}$} & Transport & Ban on 2-stroke engines, introduction of compressed natural gas vehicles in Dhaka \\
\hline & Brick kilns & Introduction of Hybrid Hoffman kilns \\
\hline & Multiple sectors & Air Pollution Reduction Strategy for Bangladesh \\
\hline Sri Lanka $^{44}$ & Transport & $\begin{array}{l}\text { Phasing out 2-stroke engines } \\
\text { Introduction of vehicular testing programmes }\end{array}$ \\
\hline \multirow[t]{3}{*}{ Nepal $^{45}$} & Transport & $\begin{array}{l}\text { Vehicle inspection and emissions testing } \\
\text { Ban on 2-stroke engines } \\
\text { Pollution cess on fuel }\end{array}$ \\
\hline & Brick kilns & Ban on movable bull trench kilns \\
\hline & Dust control & Road improvement and footpath development in Kathmandu \\
\hline
\end{tabular}

\section{Health centred environmental policy making} is required

With the multiplicity of sources, modes of exposure, and complexity of outcomes, there is no easy solution to the problem of air pollution in South Asia. While household air pollution needs targeted interventions with substitute fuels, tackling ambient air pollution, with its varied sources, requires a broader approach. Systematic collection of air quality data and a scientific approach to air quality management are essential to tackle the varied sources of emissions. South Asian countries can learn from and adapt evidence based initiatives implemented in other parts of the world such as the Clean Air Act in the US ${ }^{46}$ and China's five year, targeted 10 point action plan to improve air quality in three provinces. ${ }^{47}$ Local solutions and policies must be designed to tackle the major sources and contributors. Box 2 provides an example of a recent programme launched in India to reduce household air pollution by expanding access to clean cooking fuel.
An evidence informed, multisectoral approach to policy making is required. ${ }^{54}$ While the health sector can play a convening role on initiatives to minimise exposure and ameliorate health impacts, the onus of action lies outside, with the implementation of policies and programmes across the ministries of environment, energy, industry, and finance, among others.

The emphasis on "health in all policies" laid out in the 68th World Health Assembly's resolution on air pollution provides a roadmap to tackle a cross sectoral issue like air pollution where health is adversely affected as a result of ineffective policy making across sectors. The resolution emphasised the need for health related benchmarks of progress in air pollution control measures, and advocated health impact assessments in policy design, implementation, and evaluation related to air pollution. ${ }^{55}$ In the context of growing energy use, rapid urbanisation, and increased demand for personal and public transport, the health

\section{Box 2: Increasing access to clean cooking fuel in India}

The Indian government has historically provided a subsidy for liquefied petroleum gas (LPG). Access to this subsidy, however, was skewed heavily in favour of the urban population. ${ }^{48}$

To tackle this imbalance, the Pradhan Mantri Ujjwala Yojana was launched in May 2016 with the aim of providing 50 million rural households with subsidised LPG connections by 2019 , where hitherto they had been using solid fuels for cooking (fig 5).

This was coupled with a campaign to encourage urban recipients to give up their subsidy, and the PAHAL scheme for direct transfer of LPG subsidies to beneficiaries' bank accounts. ${ }^{490}$ The programme exceeded its connection targets in the first year. ${ }^{51}$ The investment both by way of political will and finances is vital. The question, however, of whether access equates with usage remains-newspapers have recently reported on beneficiaries dropping out after initial refills. $^{5253}$ 


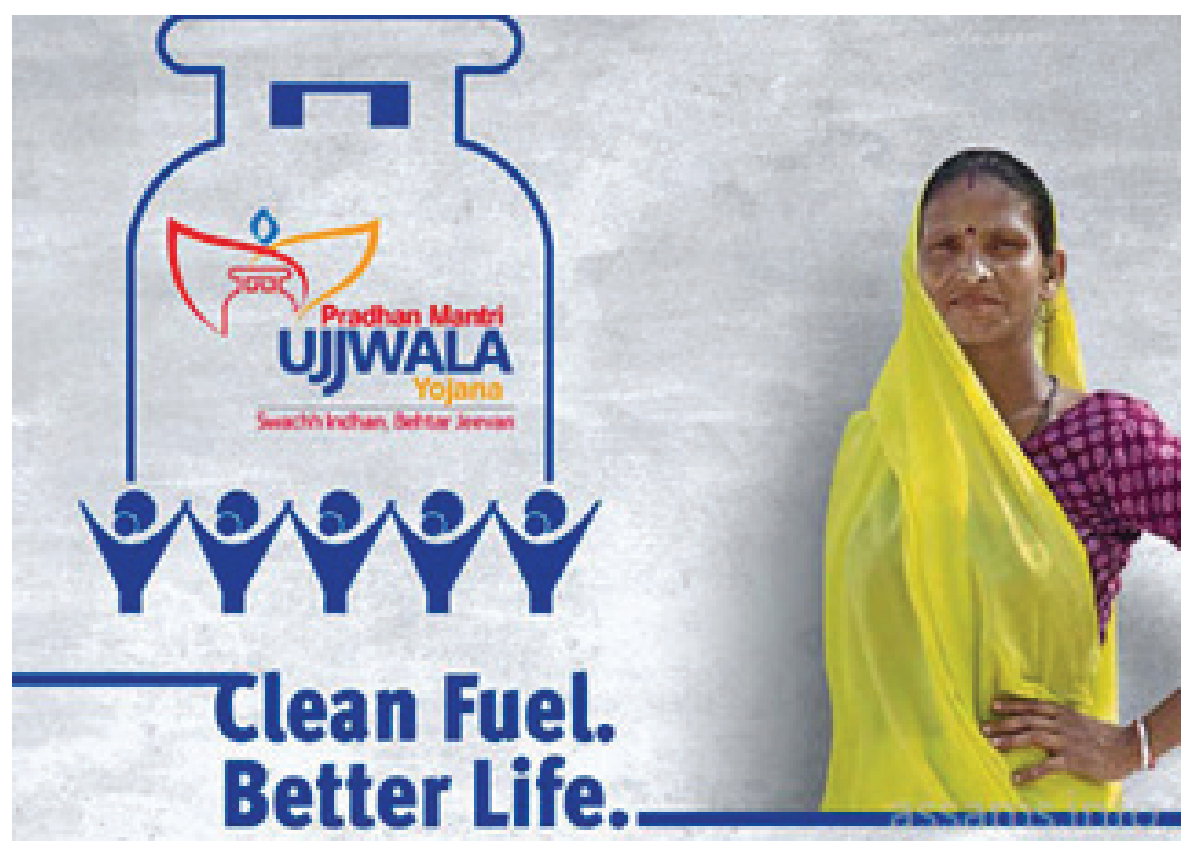

Fig 5 | An advertisement for the Pradhan Mantri Ujjwala Yojana (Source: www.assams.info/ images/2016/05/PMUY.jpg)

impacts of air pollution can be a conscience keeper for the principles of sustainable urbanisation and development.

While localised sources and emissions are important to tackle exposure, it is also vital to recognise the role of long distance and transboundary transport of air pollution in an interconnected airshed like the Indo-Gangetic Plain which links Bangladesh, India, and Pakistan. Existing political platforms, such as the South Asian Association for Regional Cooperation, must be leveraged to drive action on air quality. WHO's multisectoral action plan on non-communicable diseases provides a platform through which national and regional consensus can be fostered on the health impacts of air pollution. In addition to the nine traditional risk factors outlined in the action plan, member states of WHO's South East Asia region included the reduction of exposure to household air pollution from biomass as a target for the region. This platform can be the basis for coordinated and innovative regional action to reduce exposures and improve health outcomes.

\section{Sources and methods}

We used data from the Global Burden of Disease Study (GBD) 2015 on ambient and household exposure to air pollution and health burden estimates. Details on the methods for exposure estimation are described elsewhere. ${ }^{2930}$

We do not know of any other study that provides national level estimates for the purpose of comparison across different countries. In this context, we acknowledge the need to strengthen the local evidence base by conducting more direct epidemiological studies on the health effects of ambient and household air pollution which would accord greater confidence to the burden estimates.

During the preparation of this manuscript, the GBD estimates for 2016 were released. We believe that the minor revision in overall numbers did not necessitate shifting to the 2016 estimates for this article.

For other information covered in this article, we conducted searches on PubMed, Google Scholar, and Science Direct for relevant reviews and reports published in the region, and drew on our collective experience in this field.

Contributors and sources: BK and DB developed the outline for the paper, to which all other authors contributed. $B K, M B, K B, A R S, D B$, and $B A B$ contributed sections to the paper, drawing on their previous work and research from their respective countries. BK consolidated drafts. BK and MB coordinated revisions. All authors reviewed and approved the final manuscript.

Competing interests: We have read and understood BMJ policy on declaration of interests and have no relevant interests to declare.

Bhargav Krishna, manager (technical)

Kalpana Balakrishnan, associate dean (research) and director

Amna R Siddiqui, associate professor

Bilkis A Begum, chief scientific officer

Damodar Bachani, director

Michael Brauer, professor

${ }^{1}$ Centre for Environmental Health, Public Health Foundation of India, Gurgaon, India

${ }^{2}$ Department of Environmental Health Engineering, Sri Ramachandra University, Chennai, India

${ }^{3}$ Department of Community Health Sciences, Aga Khan University, Karachi, Pakistan
${ }^{4}$ Chemistry division, Atomic Energy Centre, Dhaka (AECD), Dhaka, Bangladesh

${ }^{5}$ School of Population and Public Health, University of British Columbia, Vancouver, Canada

Correspondence to: Bhargav Krishna

bhargavkrishna@gmail.com

1 Gakidou E, Afshin A, Abajobir A, et alGBD 2016 Risk Factors Collaborators. Global, regional, and national comparative risk assessment of 84 behavioural, environmental and occupational, and metabolic risks or clusters of risks, 1990-2016: a systematic analysis for the Global Burden of Disease Study 2016. Lancet 2017;390:1345-422. doi:10.1016/ S0140-6736(17)32366-8

2 World Health Organization. WHO Global Urban Ambient Air Pollution Database (Update 2016). 2016.

3 Shindell D, Borgford-Parnell N, Brauer M, et al. A climate policy pathway for near- and long-term benefits. Science 2017:356:493-4. doi:10.1126/ science.aak9521

4 Global Alliance for Clean Cookstoves. GACC Country Factsheets. http://cleancookstoves.org/countryprofiles/64-sri-lanka.html.

Siddiqui AR, Lee K, Bennett D, et al. Indoor carbon monoxide and $\mathrm{PM}_{25}$ concentrations by cooking fuels in Pakistan. Indoor Air 2009;19:75-82. doi:10.1111/j.1600-0668.2008.00563.x

6 Elledge MF, Phillips MJ, Thornburg VE, Everett KH, Nandasena S. A profile of biomass stove use in Sri Lanka. Int J Environ Res Public Health 2012;9: 1097-110. doi:10.3390/ijerph9041097

Balakrishnan K, Ramaswamy P, Sambandam S, et al. Air pollution from household solid fuel combustion in India: an overview of exposure and health related information to inform health research priorities. Glob Health Action 2011. www.ncbi.nlm.nih.gov/pmc/ articles/PMC3188887.

8 Clark ML, Peel JL, Balakrishnan K, et al. Health and household air pollution from solid fuel use: the need for improved exposure assessment. Environ Health Perspect 2013;121:1120-8.

9 World Health Organization. WHO Air quality guidelines for particulate matter, ozone, nitrogen dioxide, and sulfur dioxide : global update 2005 summary of risk assessment. 2006. http://www.who. int/iris/handle/10665/69477.

10 Bonjour S, Adair-Rohani H, Wolf J, et al. Solid fuel use for household cooking: country and regional estimates for 1980-2010. Environ Health Perspect 2013;121:784-90. doi:10.1289/ ehp.1205987

11 Chafe ZA, Brauer M, Klimont Z, et al. Household cooking with solid fuels contributes to ambient PM2.5 air pollution and the burden of disease. Environ Health Perspect 2014:122:1314-20.

12 Forouzanfar MH, Alexander L, Anderson HR, et al. GBD 2013 Risk Factors Collaborators. Global, regional, and national comparative risk assessment of 79 behavioural, environmental and occupational, and metabolic risks or clusters of risks in 188 countries, 1990-2013: a systematic analysis for the Global Burden of Disease Study 2013. Lancet 2015;386:2287-323. doi:10.1016/S01406736(15)00128-2

13 The air pollution knowledge assessment (APnA) city program. www.urbanemissions.info/wp-content/ uploads/apna/docs/apna_program_summary_ booklet.pdf.

14 Begum BA, Hopke PK, Markwitz A. Air pollution by fine particulate matter in Bangladesh. Atmos Pollut Res 2013;4:75-86doi:10.5094/APR.2013.008.

15 Stone E, Schauer J, Quraishi TA, Mahmood A. Chemical characterisation and source apportionment of fine and coarse particulate matter in Lahore, Pakistan. Atmos Environ 2010;44:1062-70doi:10.1016/j. atmosenv.2009.12.015.

16 Shahid I, Kistler M, Mukhtar A, et al. Chemical characterization and mass closure of $\mathrm{PM}_{10}$ and $\mathrm{PM}_{2.5}$ at an urban site in Karachi, Pakistan. Atmos Environ 2016;128(Supplement C):114-23. doi:10.1016/j.atmosenv.2015.12.005. 
17 Khanum F, Chaudhry MN, Kumar P. Characterization of five-year observation data of fine particulate matter in the metropolitan area of Lahore. Air Qual Atmos Health 2017;10:725-36. doi:10.1007/ s11869-017-0464-1

18 Cohen AJ, Brauer M, Burnett R, et al. Estimates and 25 -year trends of the global burden of disease attributable to ambient air pollution: an analysis of data from the Global Burden of Diseases Study 2015. Lancet 2017;389:1907-18. doi:10.1016/S01406736(17)30505-6

19 Nasir ZA, Murtaza F, Colbeck I. Role of poverty in fuel choice and exposure to indoor air pollution in Pakistan. J Integr Environ Sci 2015;12:107-17doi:10 .1080/1943815X.2015.1005105.

20 Siddiqui AR, Gold EB, Yang X, Lee K, Brown KH Bhutta ZA. Prenatal exposure to wood fuel smoke and low birth weight. Environ Health Perspect 2008;116:543-9. doi:10.1289/ehp.10782

21 Central Pollution Control Board. Study on ambient air quality, respiratory symptoms and lung function of children in Delhi. 2008.

22 Cohen AJ, Brauer M, Burnett R, et al. Estimates and 25 -year trends of the global burden of disease attributable to ambient air pollution: an analysis of data from the Global Burden of Diseases Study 2015. Lancet 2017;389:1907-18. doi:10.1016/S01406736(17)30505-6

23 Clifford A, Lang L, Chen R, Anstey KJ, Seaton A. Exposure to air pollution and cognitive functioning across the life course-a systematic literature review. Environ Res 2016;147:383-98. doi:10.1016/j. envres.2016.01.018

24 Brook RD, Rajagopalan S, Pope CA 3rd, et al. American Heart Association Council on Epidemiology and Prevention, Council on the Kidney in Cardiovascular Disease, and Council on Nutrition, Physical Activity and Metabolism. Particulate matter air pollution and cardiovascular disease: An update to the scientific statement from the American Heart Association. Circulation 2010;121:2331-78. doi:10.1161/CIR.0b013e3181dbece1

25 Hajat A, Diez-Roux AV, Adar SD, et al. Air pollution and individual and neighborhood socioeconomic status: evidence from the Multi-Ethnic Study of Atherosclerosis (MESA). Environ Health Perspect 2013;121:1325-33.

26 Central Pollution Control Board. National air quality monitoring. www.cpcb.nic.in/Network.php.

27 Cohen AJ, Brauer M, Burnett R, et al. Estimates and 25 -year trends of the global burden of disease attributable to ambient air pollution: an analysis of data from the Global Burden of Diseases Study 2015. Lancet 2017;389:1907-18. doi:10.1016/S01406736(17)30505-6

28 Smith KR, Bruce N, Balakrishnan K, et al. HAP CRA Risk Expert Group. Millions dead: how do we know and what does it mean? Methods used in the comparative risk assessment of household air pollution. Annu Rev Public Health 2014:35:185-206 doi:10.1146/annurev-publhealth-032013-182356
29 Henneman LRF, Liu C, Mulholland JA, Russell AG Evaluating the effectiveness of air quality regulations: A review of accountability studies and frameworks. I Air Waste Manag Assoc 2017;67:144-72. doi:10.10 80/10962247.2016.1242518

30 Sánchez-Triana E, Enriquez S, Afzal J, Nakagawa A Shuja Khan A. Cleaning Pakistan's air: policy options to address the cost of outdoor air pollution.World Bank. 2014. http://documents.worldbank.org/ curated/en/701891468285328404/pdf/890650P UBOClea00Box385269B00PUBLICO.pdf.

31 Ministry of Climate Change. National Climate Change Policy. 2012. www.gcisc.org.pk/National_Climate_ Change_Policy_2012.pdf.

32 United Nations Environment Programme. Air quality policies: Pakistan. 2015. https://wedocs.unep.org/ bitstream/handle/20.500.11822/17077/Pakistan. pdf? sequence $=1$ \&isAllowed $=\mathrm{y}$.

33 Mir KA, Purohit P, Goldstein GA, Balasubramanian R. Analysis of baseline and alternative air quality scenarios for Pakistan: an integrated approach. Environ Sci Pollut Res Int 2016;23:21780-93. doi:10.1007/s11356-016-7358-x

34 Pakistan's intended nationally determined contribution. www4.unfccc.int/Submissions/INDC/ Published\%20Documents/Pakistan/1/Pak-INDC.pdf.

35 Mohile SSBSVI. challenges and opportunities for India's auto industry. 2017. www.livemint. $\mathrm{com} /$ Industry/b5VcxRbUqSjDLySxl4Cr0O/BS-VIChallenges-and-opportunities-for-Indias-autoindustr.html.

36 Central Pollution Control Board, Ministry of Environment, Forest, and Climate Change, Government of India. Industry specific standards. www.cpcb.nic.in/Industry_Specific_Standards.php.

37 Ministry of Petroleum and Natural Gas, Government of India. About PMUY. www.pmujjwalayojana.com/ about.html.

38 Thakur J, Halder R. Delhi finally has an action plan to combat air pollution, here's how you can help. 2017. www.hindustantimes.com/delhi-news/ delhi-finally-has-an-action-plan-to-combat-airpollution-here-s-how-you-can-help-too/story2R8HGYVHM1BZnhtnlbbNf).html.

39 Environment Pollution (Prevention and Control) Authority for the National Capital Region. Comprehensive action plan for air pollution control in the National Capital Territory. 2017. www.epca.org. in/EPCA-Reports1999-1917/Report-draft-no.66.pdf.

40 Singh RK. Brick kilns shifting to cleaner technology, but progress is slow 2017. www.downtoearth.org.in/ news/brick-kilns-shifting-to-cleaner-technology-butprogress-is-slow-58559.

41 Begum BA, Nasiruddin M, Randal S, Sivertsen B, Hopke PK. Identification and apportionment of sources from air particulate matter at urban environments in Bangladesh. Br J App Sci Technol. 2014;4:3930-55doi:10.9734/ BJAST/2014/11247.

42 World Bank. Modern brick kilns yield development benefits in Bangladesh. 2016. www.worldbank.org/ en/news/feature/2016/07/20/modern-brick-kilnsyield-development-benefits-in-bangladesh.

43 Department of Environment, Government of Bangladesh. Air pollution reduction strategy for Bangladesh. 2012. http://old.doe.gov.bd/ publication_images/60_air_pollution_reduction_ strategy.pdf.

44 Nandasena YLS, Wickremasinghe AR, Sathiakumar N. Air pollution and health in Sri Lanka: a review of epidemiologic studies. BMC Public Health 2010;10:300. doi:10.1186/1471-2458 10-300

45 Clean Air Network Nepal. Air quality status and management in Kathmandu Valley. www. cen.org.np/uploaded/AQ\%20Status\%20 and\%20Managment\%20in\%20KV Maya\%20 Factsheet\%205.pdf.

46 California Air Resources Board. History. https://ww2. arb.ca.gov/about/history.

47 Zhang C. Can China meet its 2017 air quality goals? 2017. www.chinadialogue.net/article/show/single/ en/9574-Can-China-meet-its-2-17-air-quality-goals-

48 Lahoti R, Goutam P, Suchitra JY. Subsidies for whom? The case of LPG in India. www.iimb.ac.in/sites/ default/files/subsidies_for_whom.pdf.

49 Ministry of Petroleum and Natural Gas. GiveltUp LPG Subsidy. www.givitup.in.

50 Ministry of Petroleum and Natural Gas, Government of India. PAHAL-direct benefits transfer for LPG(DBTL) consumers scheme. http://petroleum.nic.in/dbt/ whatisdbtl.html.

51 Kumar S. Pradhan Mantri Ujiwala Yojana: $3 \mathrm{cr}$ LPG connections already issued, Oil Min seeks to serve another $3 \mathrm{cr}$ beneficiaries. Financial Express. 2017. www.financialexpress.com/india-news/ pradhan-mantri-ujjwala-yojana-3-cr-lpg-connectionsalready-issued-oil-min-seeks-to-serve-another-3-crbeneficiaries/914691/lite.

52 Iha DK. Modi's pet Ujiawala scheme wobbles as many beneficiaries drop out after their first LPG cylinder. 2017. https://scroll.in/article/839961/modis-petujjawala-scheme-wobbles-as-many-beneficiariesdrop-out-after-their-first-lpg-cylinder.

53 Kishore R. India's poor are not using LPG cylinders they got under Ujjwala scheme. 2017. www.livemint com/Politics/oqLQDFKNuMdbmLEVL88krN/Indiaspoor-are-not-using-LPG-cylinders-they-got-underUjjw.html.

54 Ministry of Heath and Family Welfare, Government of India. Report of the steering committee on air pollution and health related issues. 2015. http://ehsdiv.sph.berkeley.edu/krsmith/ publications/2015/MoHFW\%20AP\%20Steering\%20 Com.pdf.

55 68th World Health Assembly. Health and the environment: addressing the health impact of air pollution. 2015. http://apps.who.int/gb/ebwha/ pdf_files/WHA68/A68_18-en.pdf

Cite this as: BM/ 2017:359:j5209

http://dx.doi.org/10.1136/bmj.j5209 